\title{
Muslims and depression: the role of religious beliefs in therapy
}

\author{
Shaista Meer * and Ghazala Mir \\ *Correspondence: s.m.meer@leeds.ac.uk \\ CrossMark \\ Flick for updates
}

Academic Unit of Psychiatry and Behavioural Sciences, Leeds Institute of Health Sciences, University of Leeds, United Kingdom.

\begin{abstract}
Background: Policy and practice guidelines in the UK and elsewhere promote the use of culturally appropriate treatment for clients from minority groups. The literature demonstrates religious coping can be effective in reducing levels of depression and that people from Muslim backgrounds are likely to use religious coping techniques.

Methods: This study explored the possibility of adapting an existing therapy to meet the needs of Muslims with depression. Behavioural Activation (BA) was selected as an appropriate approach based on its focus on behaviour linked to values. To investigate which adaptations were needed, interviews were carried out with practitioners $(n=26)$ and Muslim service users ( $n=4)$. Data was organised into themes adapted from a previous cultural adaptation of BA. Three advisory groups were consulted on the content of the thematic framework.

Results: The findings supported the incorporation of religious teachings within psychological therapies and highlighted the importance of therapists creating space to discuss religion with clients who wish to. Therapists recognised religion could be a useful resource, however, often felt ill equipped to engage with a religious framework within therapy.

Conclusions: Practitioners, including those from Muslim backgrounds, require training and guidance regarding attention to religious beliefs within therapy. Practitioners need to be prepared to develop their knowledge of religious beliefs and cultural issues that may arise for clients from the communities with which they work.
\end{abstract}

Keywords: Depression, islam, religion, therapy, psychology, adaptation psychological

\section{Introduction}

Muslims make up the second largest religious group in Britain [1]. A census of UK inpatients and out patients in National Health Service (NHS) and independent mental health services showed that $4 \%$ of the 31,786 people recorded identified themselves as Muslim [2]. The National Institute for Clinical Excellence [3] and the Department of Health [4,5] promote the use of culturally appropriate treatment for clients from minority ethnic and faith groups. Van Loon et al., [6] have argued that higher rates of depression in ethnic minority groups means there is a need for culturally adapted interventions; and having an intervention that focuses on values and beliefs specific to the cultural group makes treatment more effective. Fernando [7] has commented that mental health practitioners are not free from biases or making value judgements on the individuals they are treating; having a better understanding of the culture or values of patients may lead to better service provision with regards to working with cultural diversity. However, little evidence about how to adapt therapeutic interventions for minority religious groups is available from reviews of clinical trials and interventions [8].

\section{Religion and wellbeing}

The concept of wellbeing has been linked to mental health in terms of 'the absence of mental disorder and the presence of positive psychological resources'; [9] and the need for therapy to influence an individual's wellbeing through an increase in postive emotions which in turn may improve their physical state (which may have been effected by their depressed emotional state) [10].

There is a significant body of literature indicating that religion may influence wellbeing through pathways that are behavioural, psychological, social and physiological; [11] and in the wider literature, there is evidence that interventions that include faith are effective in the treatment of depression. Religious coping in response to stress can be both positive and negative in style. 'Positive religious coping' has been associated with reduced levels of depression and the use of an internalised spiritual belief system, providing strategies that promote hope and resilience [12]. Religious beliefs and practices that encourage a proactive approach to dealing with problems, are more likely to help people overcome depression [12b]. Conversely, aspects of religion that are negative or unhelpful, for example perceiving illness as being abandoned or punished by God, are defined as 'negative religious coping', and have been found to increase depression and anxiety $[12,13]$. Ventis [14] found that those who follow an intrinsic form of religiosity tend to report being free from anxieties and guilt. 
Cinnirella and Loewenthal (1999) reported that the Muslim respondents in their study showed the highest amount of agreement (92\% of Muslim respondents), compared to participants from other religious backgrounds, when it came to considering religion as a form of treatment for depression. Evidence about the kind of religious coping used by Muslims is lacking, however, although El Azayem et al., (1994) suggest that there is an inherent focus on positive coping within the religious framework of Islam [16].

Research indicates that interventions drawing on faith can be effective in addressing and preventing depression [8] and improving quality of life [17]. A review of evidence, across diverse religious groups suggests that religious activities including private prayer and collective worship can contribute to wellbeing and decrease isolation [14].

Evidence suggests that people from Muslim backgrounds are more likely to use religious coping techniques than individuals from other religious groups in the UK [18]. Bobat [19] reports improvements in a group of Muslim men in the UK with mental ill health who found that attending the mosque was a useful coping strategy; and a study with 64 Muslim patients in Pakistan reported a reduction in depression during the fasting month of Ramadan.

Religious coping strategies for depression have been integrated into a range of psychological therapy approaches [20-22] and Townsend's [8] review of clinical trials found therapeutic approaches incorporating religion as effective as those adopting a secular approach.

\section{Other influences on health behaviour}

Most Muslims in the UK have origins in non-Western countries and religious beliefs and practices are often intertwined with other aspects of culture and identity, such as ethnicity and gender [22]. It has been suggested that people from nonWestern backgrounds may express emotional distress in physical terms or interpret symptoms of psychological distress as physical illness [23]; this generally leads to the individual being described as somatising psychological distress. However, Gureje et al., [24] large empirical study covering a range of international sites demonstrated that somatisation was not specific to particular cultures. Ryder et al., (2002) highlight that individuals described as somatising may be considered to be denying any emotional distress, whereas it has been suggested that the definition of somatisation can vary and refers to some crossover between the physical and emotional-however it may be expressed [23].

Differential diagnosis patterns have been shown to exist; Muslims are often not referred for psychological therapies, and are more likely to self-refer [25]. Bhui et al., [26] found that even when a Punjabi patient is identified as having psychological distress, GPs may conclude that management of the disorder may be handled differently. Studies of different conceptual models of depression have found that people from White/ Western backgrounds are more likely to follow a biopsychiatric model, and expect depression to require professional treatment $[27,28]$. In contrast, people from minority ethnic communities in the West are more likely to describe their psychological problems in relation to a situational model, that is, in terms of social and relationship issues $[27,29]$. Halbriech et al., [30] highlight that whilst some cultures may favour somatic or psychological explanations, this does not indicate that one explanation is superior to the other; what is normal and acceptable varies from culture to culture.

\section{The present study}

The current study involved an interdisciplinary and multicultural research partnership and aimed to explore whether it was possible to adapt an existing therapy to meet the needs of Muslims with depression. The evidence linking religious behaviour with decreased depression suggested a behavioural approach was likely to be most appropriate and Behavioural Activation (BA) was selected because of its emphasis on client values [31-33]. As an approach, evidence indicates that BA is an effective treatment for depression and a growing area of therapy [31-34]. A 'culturally sensitive' version of BA has already been developed for Latino populations in the US, providing evidence of its capacity to be culturally adapted for a specific group [35].

The focus of this study was to make this therapeutic modality more appropriate and sensitive to the needs of Muslims with depression, rather than to create a new psychological therapy. This is an approach supported by previous studies that suggest adapting interventions already in use are not only effective in raising awareness of a more appropriate intervention but adapted tools are a more effective method of implementing behaviour change and reducing service provision inequalities [36]. In order to investigate the adaptations needed, we interviewed practitioners with experience of treating Muslim clients and clients with experience of using mental health services. Participants were asked about their experiences and understandings of depression in Muslim communities; their views on religion and spirituality within therapy, and what therapists should bear in mind when working with Muslim clients.

In this paper we present some of the key findings that informed the adaptations that were made to the psychological therapy manual.

\section{Methods \\ Sample}

The method employed to recruit Key Informants was the snowballing' approach [37] by initially using contacts known to the research partners and building momentum from these. Sample size was determined to achieve 'saturation' i.e., capture a range of experiences without being repetitious [38], based on the experience of the research team. Thirty Key Informants, were selected on the basis of experience of delivering mental health services to people from Muslim backgrounds 
$(n=26)$ or as Muslim service users $(n=4)$. There were 17 male and nine female practitioners, including a mental health support worker; five clinical psychologists; a GP; two service managers and three psychiatrists. Health practitioners were based across England and Muslim clients (two male and two female) in Bradford. Themes arising from KI interviews were presented to a Muslim Service Users Advisory Group, drawn from existing users of a voluntary sector Black and Minority Ethnic (BME) mental health organisation ${ }^{a}$ in Bradford, for validation and additional feedback.

Key informants were interviewed using a semi structured topic guide developed from a literature review of studies on religion and depression, with a particular focus on interventions for treating Muslim clients with depression [39]. Practitioners' views were explored in such areas as: the use of religion or spirituality in therapy; involvement of family members and other issues that practitioners should bear in mind when working with Muslim clients. Clients were asked similar questions, with the focus being on their experience of receiving services. All participants provided written consent to be interviewed.

\section{Analysis}

Interviews were transcribed, translated where necessary (if Key Informants carried out their interview in a language other than English), and coded using NVivo 8 software. Based on the Framework Analysis approach [40] data was organised into seven main themes adapted from a previous cultural adaptation of BA [35]. These themes were divided in to a further 24 subthemes [41].

Three advisory groups, made up of practitioners and clients, were consulted on the content of the thematic framework. Two researchers independently checked coding themes against close readings of transcripts to ensure coding was concurrent to the themes. The coding framework was then applied to further transcripts and interpretations cross-checked for $20 \%$ of interviews. Preliminary analysis was validated by the project advisory groups.

Analysis brought together supporting and disproving evidence for interpretive propositions; deviant cases were used to enhance validity [41] and develop explanations encompassing diverse viewpoints [42].

Analysis was informed by wider aspects of literature on religion and mental health focusing on comparisons between diverse respondent perspectives. Reliability and objectivity were achieved through the systematic and documented collection of data and reflexive approaches during all stages of research [40].

\section{Results \\ Spiritual understandings of health}

Participants highlighted that whilst religion is not a central aspect of identity for every Muslim, Islam is likely to have informed values with which many Muslims may have been raised. A client's relationship with God is likely to feature for most people from Muslim backgrounds, including those who are ambivalent about religion or struggling to make sense of their identity. Key Informants suggested that therapists could gauge how important Islam might be by getting a person to describe their typical day.

"Even with young people who seem to be rebelling against everything. If I check out and I just... you know - without any judgement or expectation on my part - [...] if they are talking what their parents say about God or something. And I say what do you think? What is surprising for me always is even the most rebellious adolescents often say, "Well actually, I do talk to God sometimes." And so then it's like an opening, so I think they need to feel like you're open to that too [...]. And if they think the professional isn't going to be sympathetic or understanding of religion or spirituality they just won't bring it up.

Clinical psychologist

"If the person says that I pray regularly, in the morning and whatever. Erm, so it's from the beginning of the day to the end of the day, what do you do in that day? What's important?"

Mental Health service manager

Muslim Key Informants expressed the belief that God gives health, the ability to recover and only God has the power to heal. Other Key Informants pointed out that this understanding could lead to both stigmatising and accepting attitudes of depression. A negative interpretation of religious teachings would, for example, interpret poor health as a reflection of poor religiosity. Someone who believed they were being punished by God would be more likely to consider depression as deserved with adverse consequences for hope of recovery. In contrast, a more positive interpretation would interpret illness or difficulties as a test from God, something that individuals had inherent strength to deal with. Spirituality was often seen as an integral aspect of identity for Muslims and a potential resource:

"So their whole notion of self is already very different to a
Westernised mind, body kind of idea - split idea of self. It's
one in which mind body and spirit are connected, and so the
way in which they understand themselves is with all of those
dimensions. And traditionally within those religions, spirituality
was also partly one of the techniques or the method that was
used to resolve challenges or difficulties in life." Clinical psychologist

Key Informants mentioned that in some cases families may not accept a mental health diagnosis and seek a supernatural explanation. Belief in supernatural causes contributing to or being a reason for mental illness is considered acceptable by some Muslim scholars [43]. However, the social stigma faced by individuals with depression, could sometimes be 
associated with such beliefs:

"It's a double edged stigma, in that it's not just the stigma of mental health but the stigma of home concepts [sic] of Jinns, which some communities will feel quite strongly about and the fact that other times they might feel that their whole illness is black magic and want to work in that context."

Community Development Worker

Key Informants suggested it was important for therapists to accept conceptual models of depression relating to supernatural causes, whether or not they themselves believed in them. At the same time, clients should be encouraged not to discount psychological interventions or medication which could still be effective, whatever the cause of depression.

\section{Positive religious coping}

Adhering to religious practices and acting on religious beliefs was perceived as providing a more hopeful perspective and encouraging resilience.

"There are people that I see who are Muslims who are very much practicing Muslims and they get a lot out of that spirituality side [.....] they seem to be able to cope with issues better, partially because again, because of their belief systems, because they accept, you know from a Muslim perspective that this is, 'this is from Allah, this is a test or this is something that I'm going through, this is a... this is all part and parcel of me being here [....] and therefore it becomes a kind of coping mechanism to enable you to continue to progress in your lives..."

General practitioner

Key Informants felt that religion could help individuals come to an understanding about difficulties and there were parallels between therapeutic approaches and Islamic principles. For example, Islam encourages individuals to take responsibility for themselves and their actions, and to encourage alternatives to negative thoughts. Turning to God provided strength, especially for those individuals who felt isolated. Similarly the act of repentance helped individuals focus their attention on more positive elements of their situation, preventing them falling into despair, and in some cases, against suicide.

\section{Negative religious coping}

The function of client behaviour motivated by religious beliefs was seen as a key criterion for whether religious interpretations needed to be challenged through reference to more positive or balanced teachings.

Key Informants gave examples of instances where religious beliefs may contribute to mental health difficulties, for example, following particular interpretations of religious teachings. These interpretations may often be linked to culturally biased emphasis on particular aspects of Islam or misinformation about religious teachings. Practitioners with little knowledge of the difference between cultural practises and scriptural teachings could feel unable to challenge such beliefs:

"It's always the .., the husband has rights over his wife, the parents have rights over the children and its always somebody who is in authority has rights over the person who doesn't so, it's not the other way round and it's ... I think it's the Imaams of the Mosque that need to say these things and tell the community that er, that, the children have rights as well [...] it's a two way thing but I've lived all my life thinking it was just one way."

Service user

It was suggested that unhelpful guilt could be stimulated by focus on religious beliefs, for example non-observance could make clients feel unworthy of God's mercy; discouraging individuals to draw on religion as a resource. Key Informants, however, felt that this negative focus could be challenged through Islamic teachings focusing on God's mercy and forgiveness. Promoting small behavioural steps in line with the client's values again demonstrated a parallel between Islam and widely accepted therapeutic approaches [44].

\section{Discussing religion}

There was inconsistency amongst practitioners regarding confidence in engaging with clients' religious identity. Whilst all acknowledged its importance, there was uncertainty about what was acceptable within the boundaries of professional conduct. Many professionals felt the client should introduce this issue and some Muslim professionals felt it would be 'frowned upon' by colleagues to interact with clients in ways that acknowledged their shared identity. It was felt that professional training did not equip practitioners to deal with clients' religious identity, therefore some had sought alternative sources to develop their skills:

"I have to say my psychotherapy training didn't prepare me for asking questions about religion and spirituality at all. It's only years of [...] attending seminars and study days and being linked with a couple of scholars who have really answered my questions, that I've really been able to develop my own personal as well as theoretical understanding of religion and spirituality".

Clinical Psychologist

These respondents felt that making space within therapy to discuss religion was a key process for understanding the client and assessing whether, or how, religious values might be incorporated.

Where religious identity was important, some Key Informants used Quranic teachings to help clients work through problems such as difficult family relationships. Teachings from the Qur'an and Sunnah ${ }^{\mathrm{b}}$ were sometimes used to challenge understandings of oppressive relationships and promote alternative understandings. Drawing on the biography of the Prophet Muhammad and those close to him could also help with 
particular ideas about gender relationships, support confidence building and assertiveness for women:

\begin{abstract}
"When you look at the wife of the Prophet, sallalahu wassallam [Peace be upon him] you know, business woman, educated, you know it's kind of like wow, women are like yes we didn't know about that. [...] And I think that that gives people confidence in think that, you know, wow if all those 1400 years ago that was... and it's examples of people, I think that's what really, really helps. And I mean in terms of scholars, like Hazrat Aisha Saddiqah, [...] she was the biggest scholar [...]. So when you talk to women about issues like this and you talk to them that how Islam treats women and it then gives them that boost and that confidence and that self esteem".

Community mental health service manager
\end{abstract}

\section{Client-therapist match}

Issues relating to engagement and trust were recurrent within the data; for example whether the therapist was open to using religion and spirituality within therapy. Therapists from a similar background to the client were more likely to understand cultural metaphors and references. However, a shared background could sometimes lead to practitioners crossing professional boundaries:

"The medical assessor said [...] you just need to get married or
have a girlfriend and it'll cure all your problems, all your
depression will go away and you won't need these tablets
and [...] I think he was using that because he thought he could
get away with me because of he's Asian you know."

Service user

Muslim clients may prefer a therapist from a different background if they had concerns regarding confidentiality, felt ambivalent about religion or embarrassed about disclosing low religious observance. Some level of religious and cultural knowledge on the part of the therapist was seen as necessary to facilitate engagement; such knowledge could support therapists to help clients find solutions from within their own value framework:

"I think it helps if they know a little bit about the religion or at least be curious about the religion [...] when I work with anyone from any kind of culture I believe that ultimately within their own cultural system there will be ways of dealing with those difficulties."

Clinical Psychologist

Trust, empathy, compassion and openness to understanding religious beliefs were found to be the most important qualities for therapists regardless of background. Understanding the boundaries of one's own expertise was also essential:

"There comes a point of which, even if you are...a... Muslim psychologist, you draw the line and you say 'that's outside my sphere of competence' and your sphere of competence is often defined by the body of knowledge that you're drawing on, ultimately [....]. You shouldn't be doing anything as a professional or psychological therapist that isn't backed up by a body of knowledge."

Clinical Psychologist

\section{Strategies to use the family}

Findings corroborated existing evidence that involving family can be important to Muslim clients [45]. Key Informants pointed out that family dynamics could affect the ability of the individual to access healthcare. For example relying on the help of a family member who speaks English or drives; and lack of support within the family could exacerbate depression or prevent individuals from seeking help.

Some Key Informants felt that family commitments could impact on engagement with therapy, for example, completing homework tasks:

"A lot of the time at home there's lots of things: there's children, there's families there [are] things that just will not give them the space to do their homework."

Primary Care Trust manager

Key Informants felt that families were an underused resource; relatives could support the individual to make time and be motivated to do homework assignments that they might otherwise struggle to complete. At the same time, social stigma relating to depression could extend to a fear of family members finding out and labelling individuals in derogatory terms such as paaghal (mad) or challa ('simple'). Key Informants felt that people with depression were often considered unable to function properly, overlooked or taken advantage of by family.

\section{Sensitivity to support and resources available}

Key Informants suggested that partnering with faith-based or BME community organisations could support the development of cultural sensitivity amongst therapists. For example religious study circles offered peer support and could help people feel a sense of 'belonging':

"It reduces isolation, it reduces fear, it builds selfesteem, confidence and [...] it's like a breath of fresh air for them away from the social dynamics and the problems they're experiencing at home. They feel coming out to a service who understand their problem, understand the depression as a way of recovery for them."

Community mental health service manager

Key Informants felt that placing interventions in community settings could also help reduce stigma. Some practitioners had already worked with imams to promote awareness of mental illness within Muslim communities or to challenge unhelpful community practices that contribute to depression. 
However, there were also reports of unscrupulous 'faith healers' exploiting those with mental illness financially and of damaging advice from some imams.

Partnership approaches were seen as important to improved awareness and attitudes in both sectors and to ensuring mental illness did not go untreated.

\section{Social context}

Key Informants referred to the diversity within Muslim communities regarding the influence of social contexts. Older adults were often less educated than their children and less able to draw on their previous life experience to maintain a significant role:

"Older people have a lot of depression because it's a loss... [...] back home, it's like you know, more older you get, more wiser that you are - you have a better status there."

Psychotherapist

The UK context could also cause problems for young people when their religious values prohibited aspects of a desired lifestyle:

"The fact that this person's got an identity crisis and saying"l
want to be more religious' then he's got a goal where he's
saying that he wants a girlfriend."
Psychological Wellbeing Practitioner

Racism was also highlighted as an important aspect of the social context for Muslim communities in the UK. One service user described increased feelings of isolation when racism was left unchallenged in the mental health support group he attended.

\section{Discussion}

\section{Importance of religion}

Our fieldwork confirmed the significance of a faith identity to Muslims, many of whom relate their health to their faith. Most practitioners interviewed took the approach that using religion as a resource encourages people to act on their beliefs and this concordance between values and behaviour is consistent with the approach promoted by BA [32]. Our findings indicate that religious beliefs are considered protective and encourage seeking social support, whilst acting on religious beliefs encourages resilience, hope and promotes 'positive religious coping' [12]. This finding is not surprising given existing evidence that a high proportion of Muslims feel their religious beliefs can help in the treatment of depression $[15,46]$. Regarding the wider literature on religion and mental health, our findings confirm that religious identity may influence wellbeing through various routes [11] and a belief in God has demonstrated better treatment outcomes [47].

Aspirations towards a holistic therapeutic approach and respect for cultural diversity cannot be fulfilled in relation to
Muslim clients whilst even Muslim therapists express a lack of confidence about how to engage with religious identity within therapy. Such confidence is, however, unlikely amongst therapists until the issue of religious identity is acknowledged in training. The ability to incorporate a religious dimension within therapy for clients to whom this is significant and influential may be vital to supporting effective problem solving and aiding individuals to achieve solutions in accordance with their values.

Collaborative working between therapists and those with religious expertise may be important where unhelpful interpretations of religious teachings contribute to depression. There is, however, a need to formulate more clearly how collaborative working might be developed and to identify situations in which the two approaches may be synergistic, or conflicting, before treatment pathways are developed [38].

\section{Other influences on health behaviour}

Our findings confirm that some Muslim clients may express emotional distress in somatic terms [19]. As with supernatural explanations, alternative expressions of depression should, we suggest, be accepted and treated as psychological distress and clients not persuaded to accept a Western worldview [27]. Muslims are known to be under-referred for talking therapies [25] and our evidence suggests that this could be linked to practitioners misunderstanding somatic expressions as having no psychological basis.

The social context of depression is of particular relevance to people from minority ethnic groups in the West, to which most Muslims in the UK belong $[27,29]$. Our findings confirm that social factors such as young people struggling with their identity, or older people losing a sense of purpose are particular issues that practitioners will need to understand in order to enhance their approach to working with Muslims.

\section{Client-therapist match}

Trust and empathy were considered more important for the therapeutic relationship by our respondents than a therapist's religious background. Our evidence suggests therapists should demonstrate openness to talking about religion, giving a clear message that it is acceptable and potentially helpful to talk about their beliefs, if clients wish. Our findings suggest that consistent professional practice regarding engagement with the religious identity and social context of Muslim patients is an important means of challenging stereotypes that can adversely affect healthcare [21]. A basic level of knowledge of Islam and cultural issues will facilitate such engagement. Our findings indicate that therapist knowledge in this area can reduce the risk of incorrect understandings of religious beliefs being included in therapy, for example, where the distinction between religion and culture is blurred.

\section{Strengths and limitations}

A wide variety of practitioners from different service back- 
grounds were interviewed, contributing their extensive experience of working with Muslim clients. A smaller number of clients were included in the Key Informant sample and all Muslim clients were recruited from one site; including more clients would have allowed greater exploration of diversity in relation to language and ethnicity. And although a Service User Advisory Group was involved in validating findings from the fieldwork, more research with a broader range of Muslim clients could have provided a more comprehensive understanding of their experiences and better insight into reasons for low referrals or uptake of psychological therapies.

The diversity of the Key Informants from practitioner backgrounds could be considered a strength, since this sample was greater in number and more ethnically diverse compared to the clients. Having a wider spread of different professionals in the sample meant that there was scope for more exploration of diversity within each professional group.

\section{Conclusion}

The principal finding from our data is that therapists working with Muslim clients will need to adapt current practice in order to support clients to draw on religious coping strategies. There is currently inconsistency in how practitioners respond to this client need and therefore a need for opportunities through which practitioners can develop their knowledge and skills, with guidance through training. Practitioners also need to be prepared to develop their personal knowledge of religious beliefs and cultural issues that may arise for clients from the communities with which they work.

aSharing Voices Bradford is a voluntary mental health organisation aimed at supporting the needs of people from minority ethnic groups with mental health difficulties.

http://www.sharingvoices.net/

bProphetic tradition, That is, the way in which the Prophet Muhammad conducted himself. Islamic teachings encourage Muslims to follow the Prophet Muhammad's way of life as the best example of how to live in accordance with the teachings of the Qur'an.

\section{List of abbreviations}

BA: Behavioural Activation

BME: Black and Minority Ethnic

NHS: National Health Service

\section{Competing interests}

The authors declare that they have no competing interests.

Authors' contributions

\begin{tabular}{|l|c|c|}
\hline Authors' contributions & SM & GM \\
\hline Research concept and design & -- & $\checkmark$ \\
\hline Collection and/or assembly of data & -- & $\checkmark$ \\
\hline Data analysis and interpretation & $\checkmark$ & $\checkmark$ \\
\hline Writing the article & $\checkmark$ & $\checkmark$ \\
\hline Critical revision of the article & $\checkmark$ & $\checkmark$ \\
\hline Final approval of article & $\checkmark$ & $\checkmark$ \\
\hline
\end{tabular}

\section{Acknowledgement}

This paper presents independent research funded by the National Institute for Health Research (NIHR) under its Research for Patient Benefit (RfPB) Programme (Grant Reference Number PB-PG-1208-18107). The views expressed are those of the authors and not necessarily those of the NHS, the NIHR or the Department of Health.

\section{Publication history}

Editor: Philip Michael Wilson, Brock University, Canada.

Received: 26-Mar-2014 Final Revised: 17-Apr-2014

Accepted: 24-Apr-2014 Published: 13-May-2014

\section{References}

1. Office of National Statistics. 2001. I Website

2. Care Quality Commission. Count me in 2009: Results of the 2009 national census of inpatients and patients on supervised community treatment in mental health and learning disability services in England and Wales. 2010. I Pdf

3. NICE. Guideline 90: The treatment and management of depression in adults. 2009. | Website

4. Department of Health. National service framework for mental health: modern standards and service models. 20 September 1999. 1999. London. I Pdf

5. Department of Health. Delivering race equality in mental health care: An action plan for reform inside and outside services and the Government's response to the Independent inquiry into the death of David Bennett. 2005. London.

6. Van Loon A, van Schaik A, Dekker J and Beekman A. Bridging the gap for ethnic minority adult outpatients with depression and anxiety disorders by culturally adapted treatments. J Affect Disord. 2013; 147:9-16. | Article I PubMed

7. Fernando S. Cultural diversity, mental health and psychiatry: The struggle against racism. 2013. | Book

8. Townsend M, Kladder V, Ayele $\mathrm{H}$ and Mulligan T. Systematic review of clinical trials examining the effects of religion on health. South Med J. 2002; 95:1429-34. | Article | PubMed

9. Sin NL and Lyubormisky S. Enhancing Well-Being and Alleviating Depressive Symptoms With Positive Psychology Interventions: A Practice-Friendly Meta-Analysis. J Clin Psych in Session. 2009; 65:467487. I Pdf

10. Fredrickson BL and Levenson RW. Positive Emotions Speed Recovery from the Cardiovascular Sequelae of Negative Emotions. Cogn Emot. 1998; 12:191-220. | Article | PubMed Abstract | PubMed Full Text

11. Koenig HG, Larson DB and Larson SS. Religion and coping with serious medical illness. Ann Pharmacother. 2001; 35:352-9. I Article I PubMed

12. (a)Pargament KI, Tarakeshwar N, Ellison CG and Wulff KM. Religious Coping Among The Religious: The Relationship Between Religious Coping and Well-Being in a National Sample of Presbyterian Clergy, Elders, and Members. J Scientific Study of Religion. 2001; 40:497-513. I Article

(b)Uchendu C. O. The role of religious coping, superego anxiety, social cognition and object relations on recovery from substance abuse and depression. New York, Adelphi University. 2006. I Book

13. Dew RE, Daniel SS, Goldston DB and Koenig HG. Religion, spirituality, and depression in adolescent psychiatric outpatients. J Nerv Ment Dis. 2008; 196:247-51. | Article | PubMed

14. Ventis WL. The relationships between religion and mental health. $J$ Social Issues. 1995; 51:341-355. | Article

15. Cinnirella $M$ and Loewenthal KM. Religious and ethnic group influences on beliefs about mental illness: a qualitative interview study. $\mathrm{Br} J \mathrm{Med}$ Psychol. 1999; 72 ( Pt 4):505-24. | Article | PubMed

16. El Azayem GA and Hedayat-Diba Z. The Psychological Aspects of Islam: Basic Principles of Islam and Their Psychological Corollary. International 
Meer et al. Journal of Integrative Psychology and Therapeutics 2014,

\section{J Psychology of Religion. 1994; 4:41-50. | Article}

17. Lee CC, Czaja SJ and Schulz R. The moderating influence of demographic characteristics, social support, and religious coping on the effectiveness of a multicomponent psychosocial caregiver intervention in three racial ethnic groups. J Gerontol B Psychol Sci Soc Sci. 2010; 65B:185-94. | Article | PubMed Abstract | PubMed Full Text

18. Barron LW. Effect of religious coping skills training with group cognitivebehavioral therapy for treatment of depression. Northcentral University. 2007. I Article

19. Bobat H. A User-Led Research Project into Mosque. Expoloring the benefits that Muslim men with severe mental health problems find from attending Mosque. The Mental Health Foundation. 2001. | Article

20. Paukert AL, Phillips L, Cully JA, Loboprabhu SM, Lomax JW and Stanley $M A$. Integration of religion into cognitive-behavioral therapy for geriatric anxiety and depression. J Psychiatr Pract. 2009; 15:103-12. | Article | PubMed

21. Hayes SC. Acceptance and Commitment Therapy and the New Behavior Therapies: Mindfulness, Acceptance, and Relationship. Mindfulness and acceptance: Expanding the cognitive-behavioral tradition. 2004; 1-29. | Pdf

22. Mir $\mathrm{G}$ and Sheikh A. 'Fasting and prayer don't concern the doctors ... they don't even know what it is': communication, decision-making and perceived social relations of Pakistani Muslim patients with long-term illnesses. Ethn Health. 2010; 15:327-42. | Article | PubMed

23. Ryder AG, Yang J and Heine SJ. Somatization vs. psychologization of emotional distress: A paradigmatic example for cultural psychopathology. In Lonner WJ, Dinnel DL, Hayes SA, and Sattler DN (Eds.), Online Readings in Psychology and Culture. 2002. | Book

24. Gureje O, Simon GE, Ustun TB and Goldberg DP. Somatization in crosscultural perspective: a World Health Organization study in primary care. Am J Psychiatry. 1997; 154:989-95. | Article | PubMed

25. Weatherhead $S$ and Daiches $A$. Muslim views on mental health and psychotherapy. Psychol Psychother. 2010; 83:75-89. | Article | PubMed

26. Bhui K, Bhugra D, Goldberg D, Dunn G and Desai M. Cultural influences on the prevalence of common mental disorder, general practitioners' assessments and help-seeking among Punjabi and English people visiting their general practitioner. Psychol Med. 2001; 31:815-25. | Article | PubMed

27. Karasz A. Cultural differences in conceptual models of depression. Soc Sci Med. 2005; 60:1625-35. | Article | PubMed

28. Keyes $C$. The interpretive basis of depression. In Kleinman A, and Good BJ (Eds.) Culture and depression 1985. | Book

29. Patel V. Explanatory models of mental illness in sub-Saharan Africa. Soc Sci Med. 1995; 40:1291-8. | Article | PubMed

30. Halbreich U, Alarcon RD, Calil H, Douki S, Gaszner P, Jadresic E, JasovicGasic M, Kadri N, Kerr-Correa F, Patel V, Sarache X and Trivedi JK. Culturally-sensitive complaints of depressions and anxieties in women. J Affect Disord. 2007; 102:159-76. | Article | PubMed

31. Martell CR, Addis M and Jacobson NS. Depression in context: Strategies for guided action. 2001. | Article

32. Kanter JW, Manos RC, Bowe WM, Baruch DE, Busch AM and Rusch LC What is behavioral activation? A review of the empirical literature. Clin Psychol Rev. 2010; 30:608-20. | Article | PubMed

33. Ekers D, Richards D, McMillan D, Bland JM and Gilbody S. Behavioural activation delivered by the non-specialist: phase II randomised controlled trial. Br J Psychiatry. 2011; 198:66-72. | Article | PubMed

34. Dimidjian S, Hollon SD, Dobson KS, Schmaling KB, Kohlenberg RJ, Addis ME, Gallop R, McGlinchey JB, Markley DK, Gollan JK, Atkins DC, Dunner DL and Jacobson NS. Randomized trial of behavioral activation, cognitive therapy, and antidepressant medication in the acute treatment of adults with major depression. J Consult Clin Psychol. 2006; 74:658-70. | Article | PubMed

35. Kanter JW, Santiago-Rivera AL, Rusch LC, Busch AM and West P. Initial outcomes of a culturally adapted behavioral activation for Latinas diagnosed with depression at a community clinic. Behav Modif. 2010; 34:120-44. | Article | PubMed
36. Barrera M, Jr., Castro FG, Strycker LA and Toobert DJ. Cultural adaptations of behavioral health interventions: a progress report. J Consult Clin Psychol. 2013; 81:196-205. | Article | PubMed Abstract | PubMed Full Text

37. Burgess R. In the field: an introduction to field research. 1991. | Book

38. Mason J. Qualitative researching. 2002. | Book

39. Walpole SC, McMillan D, House A, Cottrell D and Mir G. Interventions for treating depression in Muslim Patients: a systematic review. J Affect Disord. 2013; 145:11-20. | Article | PubMed

40. Ritchie J and Spencer L. Qualitative Data Analysis for Applied Policy Research. In Bryman A and Burgess R (Eds.), Analyzing Qualitative Data. 1994; 173-94. | Book

41. Silverman D. Interpreting Qualitative Data: Methods for Analysing Talk, Text and Interaction. 1993. | Book

42. Ryan M, Scott DA, Reeves C, Bate A, van Teijlingen ER, Russell EM, Napper $M$ and Robb CM. Eliciting public preferences for healthcare: a systematic review of techniques. Health Technol Assess. 2001; 5:1-186. | Article I PubMed

43. Philips A AB. Ibn Taymeeyah's Essay on the Jinn (demons). 1995.

44. Valiante WC. Family Therapy And Muslim Families : A Solution Focused Approach. WIAMH Newsletter. 2003; 2:4. I Article

45. Al-Issa I. Does the Muslim religion make a difference in psychopathology? Mental illness in the Islamic world. Al-Junun. 2000; 315-353. | Article

46. Ellison CG, Boardman JD, Williams DR and Jackson JS. Religious involvement, stress and mental health: Findings from the 1995 Detroit Area Study. Soc.Forces. 2001; 80:215-249. I Pdf

47. Rosmarin DH, Bigda-Peyton JS, Kertz SJ, Smith N, Rauch SL and Bjorgvinsson T. A test of faith in God and treatment: the relationship of belief in God to psychiatric treatment outcomes. J Affect Disord. 2013; 146:441-6. | Article | PubMed

\section{Citation:}

Meer S and Mir G. Muslims and depression: the role of religious beliefs in therapy. J Integr Psychol Ther. 2014; 2:2. http://dx.doi.org/10.7243/2054-4723-2-2 